\title{
PERKERASAN ASPAL BETON (AC-BC) LIMBAH PLASTIK HDPE YANG TAHAN TERHADAP CUACA EKSTREM
}

\author{
Sumiati $^{(1)}$, Mahmuda $^{(2)}$, A. Syapawi ${ }^{(3)}$ \\ ${ }^{1,2,3}$ Teknik Sipil, Politeknik Negeri Sriwijaya, Jl. Srijaya Negara Bukit Besar Plg 30139, email: \\ sumiati@polsri.ac.id
}

\begin{abstract}
ABSTRAK
Kerusakan jalan akhir-akhir ini semakin sering terjadi pada lapis perkerasan jalan berupa retak-retak, terkelupasnya agregat, lubang-lubang hingga amblasnya perkerasan jalan. Hal ini dapat terjadi disebabkan: tingginya temperatur permukaan jalan, intensitas curah hujan yang sulit diprediksi serta beban lalulintas yang semakin hari semakin bertambah. Aspal modifikasi dibuat dengan menambahkan bahan yang bersifat elastomer seperti karet alam, maupun karet sintetis dan bahan plastik, sehingga dapat meningkatkan sifat-sifat fisik dari aspal seperti: elastisitas, ketahanan terhadap temperatur dan dapat meningkatkan stabilitas pada campuran aspal beton. Uji coba pemanfaatan limbah plastik sebagai bahan pengganti aspal telah dilaksanakan pada jalan nasional di Indonesia maupun di manca negara, hal ini menimbulkan pro dan kontra dari aktivis lingkungan. Namun menurut beberapa sumber menyatakan bahwa aspal modifikasi ini bisa bertahan di suhu ekstrem $\left(-4,5^{\circ} \mathrm{C}\right.$ hingga $\left.80^{\circ} \mathrm{C}\right)$. Berdasarkan permasalahan diatas akan diteliti, berapa persen limbah plastik HDPE yang efektif ditambahkan pada aspal modifikasi untuk campuran Laston (AC-BC) agar tahan terhadap cuaca ekstrem. Pengujian dilakukan pada 75 benda uji dengan kadar aspal optimum 5,4 \% dan limbah plastik HDPE bervariasi $0 \%$; $2 \% ; 4 \% ; 6 \%$ dan $8 \%$ terhadap berat aspal. Untuk mengetahui pengaruh suhu dari campuran Laston, sebelum dilakukan Marshall Test, terlebih dahulu benda uji direndam pada suhu $60^{\circ} \mathrm{C} ; 70^{\circ} \mathrm{C} ; 80^{\circ} \mathrm{C}$ selama 30 menit dan $60^{\circ} \mathrm{C}$ selama 24 jam. Berdasarkan Spesifikasi Lapis Perkerasan aspal (Bina Marga revisi 3, 2010), limbah plastik HDPE yang dapat ditambahkan pada campuran LASTON (AC-BC) hanya 2-4 \% terhadap berat aspal, yang memenuhi nilai karakteristik Marshall dan tahan terhadap cuaca ekstrem.
\end{abstract}

Kata kunci: Limbah plastik HDPE, aspal beton, cuaca ekstrem

\section{ABSTRACT}

Recent road damage is increasingly common in pavement layers in the form of cracks, peeling aggregates, holes, until the pavement is inundated. This can happen because: the high surface temperature of the road, the intensity of rainfall that is difficult to predict and the traffic load that increasingly day. Asphalt modification is made by adding elastomeric materials such as natural rubber, as well as synthetic rubber and plastic materials, so as to enhance the physical properties of asphalt such as: elasticity, resistance to temperature; and can increase the stability of concrete asphalt mixture. Plastic waste utilization trials as asphalt substitute have been implemented on national roads in Indonesia as well as in many countries, leading to the pros and cons of environmental activists. However, some sources have stated that this modified asphalt can survive in extreme temperatures $\left(-4.5^{\circ} \mathrm{C}\right.$ to $80^{\circ} \mathrm{C}$ ). However, according to some sources stated that this modified asphalt can survive in extreme temperatures $\left(-4.5^{\circ} \mathrm{C}\right.$ to $\left.80^{\circ} \mathrm{C}\right)$. Based on the above issues, it was examined how much the effective percentage of HDPE plastic waste was added to modified asphalt for the Laston mixture (AC-BC) which was resistant to extreme weather. The test was conducted on 75 specimens with optimum asphalt content of $5.4 \%$ and HDPE plastic waste varied $0 \% ; 2 \% ; 4 \% ; 6 \%$ and $8 \%$ to asphalt weight. To determine the effect of temperature from the mixture of Laston, before the Marshall Test conducted, the first specimen is immersed at $60^{\circ} \mathrm{C} ; 70^{\circ} \mathrm{C} ; 80^{\circ} \mathrm{C}$ for 30 minutes and $60^{\circ} \mathrm{C}$ for 24 hours. Based on Asphalt Pavement Specification (Bina Marga Revision 3, 2010), the HDPE plastic waste that can be added to the LASTON (AC-BC) mixture is only 2-4\% of the asphalt weight, which meets the Marshall characteristics and is resistant to extreme weather.

Key words: HDPE plastic waste, concrete asphalt, extreme weather 


\section{PENDAHULUAN}

Akhir-akhir ini kerusakan jalan semakin sering terjadi. Tingginya temperatur permukaan jalan dan intensitas curah hujan yang sulit diprediksi dan beban lalulintas juga merupakan salah satu penyebab kerusakan perkerasan jalan di Indonesia ini.

Telah banyak cara yang dilakukan untuk mengurangi kerusakan yang terjadi, salah satunya adalah dengan menambahkan bahan tambah (additive) pada aspal untuk merubah sifat-sifat fisik aspal, khususnya kekerasan, kepekaan terhadap temperatur dan pengelupasan tapi hal ini tentunya memerlukan biaya tambahan yang cukup besar. Selain bahan tambah (additive), dapat juga memodifikasi aspal dengan bahan yang berunsur: karet sintetis atau buatan, juga dari karet yang sudah diolah (ban bekas), dan juga dari bahan plastik.

Menteri Pekerjaan Umum Perumahan Rakyat (PUPR) menyebut Indonesia memiliki cadangan aspal 660 juta ton. Cadangan tersebut berada di daerah Buton dan Sulawesi. Kondisi cukup miris, Indonesia memiliki kebutuhan aspal 1,2 juta ton per tahun. Dari kebutuhan itu, produsen aspal Indonesia melalui PT Pertamina (Persero) dan PT Wijaya Karya Tbk (WIKA) baru menghasilkan 600.000 ton per tahun. Sisanya, 600.000 ton harus diimpor dari luar negeri. Sedangkan Indonesia tercatat sebagai negara kedua terbesar yang melakukan pembuangan limbah plastik ke laut dengan total 1,3 juta ton tiap tahunnya. Proyek perdana telah dilakukan dengan membangun jalan aspal campuran limbah plastik berjenis kresek sepanjang 700 meter di area Universitas Udayana, Bali (Ronna, 2017). Stabilitas Marshall aspal plastik diklaim lebih tinggi 40 persen yang menjadikan kinerja dan ketahanannya lebih baik dan memiliki kekuatan tiga kali lipat dibandingkan aspal biasa. Aspal campuran ini juga bisa bertahan di suhu ekstrem $\left(-4,5^{\circ} \mathrm{C}\right.$ hingga $\left.80^{\circ} \mathrm{C}\right)$, sehingga dari segi perawatannya pun akan lebih mudah dan hemat. Selain itu aspal campuran plastik lebih ramah lingkungan, karena mampu menahan gas beracun yang dikeluarkan dari campuran aspal lainnya.

Sevil, 2016, menambahkan sebanyak 1-4\% High Density Polyethylene (HDPE) pada perkerasan lentur, didapatkan hasil bahwa dengan menambahkan HDPE sebanyak 3-4\% memberikan hasil yang baik terhadap nilai Marshall. Pada penambahan HDPE > 4\% memberikan hasil yang tidak memenuhi karakteristik Marshall, jika penambahan HDPE $<2 \%$, menjadikan campuran Aspal beton tidak fleksibel/nilai flow tidak memenuhi persyaratan spesifikasi.

Penelitian Madhava, 2017, dengan menggunakan plastik HDPE dan limbah serbuk ban karet sebagai pengganti sebagian aspal didapatkan nilai stabilitas Marshall optimum pada 5\% plastik HDPE dan 10\% limbah serbuk karet dari berat aspal berkisar $6,3 \%$ dari berat agregat.

Savita, dkk, 2016, melakukan penelitian dengan menggunakan limbah plastik sebesar: 5\%; 7,5\%; 10\% dan 12,5\% terhadap berat aspal. Aspal yang digunakan sebesar: 4,5\%; $5 \% ; 5,5 \%$ dan $6 \%$ terhadap berat total agregat yang berukuran lolos saringan 4,75 mm dan tertahan saringan 2,36 mm, didapatkan bahwa pada kadar plastik 7,5\% dan kadar aspal 6\% memenuhi persyaratan nilai Stabilitas Marshall. 
Vijay, dkk, 2016, melakukan penelitian dengan menggunakan limbah plastik HDPE sebesar: 4\%; 6\%; dan 8\% terhadap berat aspal optimum pada hotmix asphalt, di mana sebelum pengujian dilakukan perendaman terlebih dahulu pada suhu $145^{\circ} \mathrm{C}, 155^{\circ} \mathrm{C}$ dan $165^{\circ} \mathrm{C}$, selama 5 menit, 15 menit dan 30 menit didapatkan bahwa: dengan mencampurkan HDPE sebanyak $4 \%$ pada suhu $165^{\circ} \mathrm{C}$ selama 30 menit, dapat meningkatkan Stabilitas Marshall, Marshall quotient dan flow.

Anita, 2017, dengan menggunakan PP dan HDPE sebesar 0\%, 2\%, 4\% dan 6\% dari berat aspal, didapatkan bahwa nilai stabilitas, flow, VFA dan MQ memiliki kecenderungan mengalami peningkatan dengan bertambahnya kadar PP dan HDPE yang digunakan. Tetapi, nilai VIM dan VMA memiliki kecenderungan menurun dengan bertambahnya prosentase PP dan HDPE. Selain itu pengaruh penambahan PP memberikan nilai karakterisk Marshall yang lebih baik dari campuran aspal beton dengan HDPE.

Anurag and Rao, 2017, dengan menggunakan PP dan HDPE sebesar 0\%, 2\%, 4\%, 6\%, $8 \%, 10 \%$ dan $12 \%$ dari berat aspal, didapatkan bahwa nilai stabilitas, flow dan VFB cenderung mengalami peningkatan dengan bertambahnya kadar PP dan HDPE yang digunakan sampai 8\%. Penggunaan PP dan HDPE berkisar 3\%-6\% akan memberikan nilai VIM dan VMA yang memenuhi spesifikasi.

Hasil survey ditemukan, bahwa banyak limbah plastik HDPE berupa: botol-botol plastik bekas wadah: sampho, makanan, oli kendaraan yang bertanda HDPE-2, mempunyai daya tahan terhadap suhu $-40^{\circ} \mathrm{C}$ sampai $90^{\circ} \mathrm{C}$ serta titik leleh $\pm 134^{\circ} \mathrm{C}$, sedangkan aspal mempunyai titik lembek $48^{\circ} \mathrm{C}$. Jadi dengan menambahkan limbah plastik HDPE pada aspal akan menaikan titik lembeknya, sehingga menjadikan aspal modifikasi lebih tahan terhadap perubahan cuaca.

Aspal modifikasi, yang akan digunakan untuk campuran aspal beton (Laston) harus memenuhi persyaratan: daktilitas, penetrasi, titik lembek, titik nyala dan titik bakar serta berat jenis, seperti tertera pada Tabel 1. Sedangkan untuk Laston (AC-BC) agar didapat perkerasan jalan yang tahan terhadap beban lalulintas, pengelupas, suhu udara dan cuaca, durabilitas, serta kenyamanan pengendara harus memenuhi persyaratan, yaitu: rongga dalam campuran (VIM), rongga dalam agregat (VMA), rongga terisi aspal (VFA), pelelehan dan stabilitas berdasarkan Spesifikasi Umum Divisi VI Revisi 3, Bina Marga, 2010.

Berdasarkan permasalahan di atas, dengan menambahkan limbah plastik HDPE berkisar $2-8 \%$ terhadap berat aspal optimum, akan didapatkan berapa persen limbah plastik HDPE yang dapat ditambahkan dalam campuran LASTON AC-BC agar memenuhi nilai karakteristik Marshall (Spesifikasi Umum Divisi VI Revisi 3, Bina Marga, 2010) yang tahan terhadap perubahan cuaca ekstrem dan didapatkan bahan bangunan yang ramah lingkungan.

\section{METODE PENELITIAN}

Penelitian ini akan dilaksanakan di laboratorium Pengujian Bahan Teknik Sipil Politeknik Negeri Sriwijaya. Bagan alur penelitian dapat dilihat pada Gambar 1. 
Adapun alur penelitian dapat diuraikan sebagai berikut:

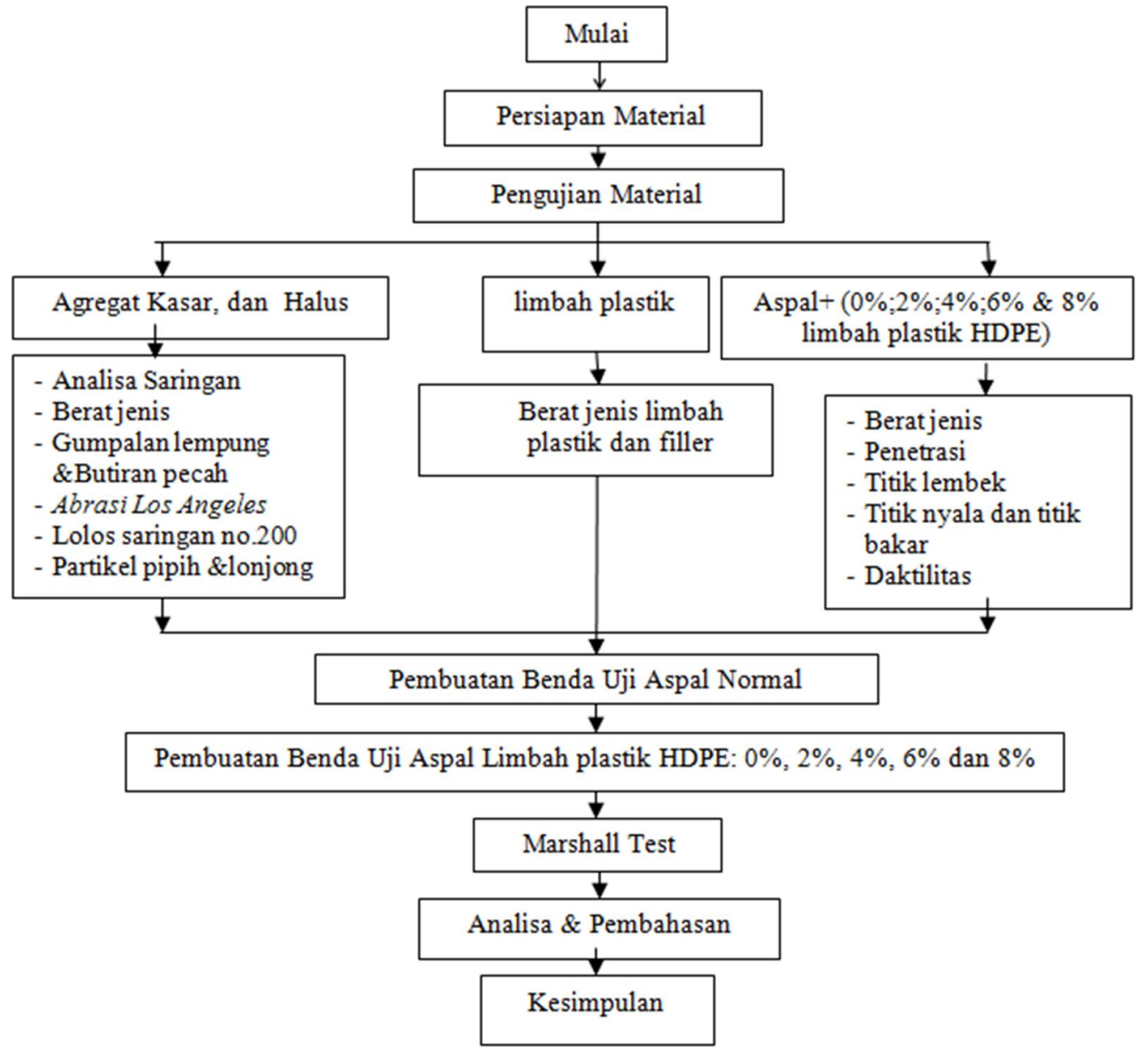

Gambar 1. Bagan Alur Penelitian

Material yang akan disiapkan yaitu berupa: Aspal pen 60/70 yang merupakan jenis aspal keras hasil destilasi minyak bumi produksi PT. Pertamina. Agregat kasar berupa batu pecah yang berasal dari Lahat. Limbah plastik yang akan digunakan adalah: botolbotol plastik bekas wadah: sampho, makanan, oli kendaraan yang bertanda HDPE-2.

Agregat halus dan kasar yang akan digunakan harus diuji terlebih dahulu untuk mengetahui sifat fisiknya apakah memenuhi persyaratan seperti: analisa saringan, berat jenis agregat kasar, berat jenis agregat halus, butiran pecah pada agregat kasar, gumpalan lempung \& butiran pecah agregat halus, partikel pipih dan lonjong, Abrasion Los Angeles, kelekatan agregat terhadap aspal dan material lolos ayakan No.200. Limbah plastik dan filler diuji berat jenisnya.

Aspal modifikasi dibuat dengan menambahkan limbah plastik HDPE bervariasi: 2\%; $4 \% ; 6 \%$ dan $8 \%$ terhadap berat aspal. Proses pencampuran dilakukan dengan cara memanaskan limbah plastik dan aspal pada tempat yang terpisah dengan suhu 155$165^{\circ} \mathrm{C}$. Campurkan kedua bahan tersebut kemudian dimixer dengan kecepatan $500 \mathrm{rpm}$ selama 15 menit, simpan diwadah yang tertutup untuk pengujian selanjutnya. Lakukan pengujian sifat fisik aspal dan aspal modifikasi meliputi: penetrasi, titik lembek, titik nyala dan titik bakar, daktilitas dan berat jenis. 
Untuk mendapatkan kadar aspal optimum terlebih dahulu dibuat benda uji Marshall berbentuk silinder dengan diameter $10 \mathrm{~cm}$ dan tinggi $\pm 7 \mathrm{~cm}$, berat \pm 1200 gram sebanyak 15 sample, dengan variasi aspal 4,5\%;5\%;5,5\%;6\% dan 6,5\% terhadap berat benda uji, di mana setiap variasi aspal dibuat masing-masing 3 benda uji. Benda Uji Aspal Limbah plastik HDPE yang ditambahkan bervariasi: $0 \% ; 2 \%, 4 \%, 6 \%$ dan $8 \%$ terhadap kadar optimum sebanyak 60 benda uji. Untuk mengetahui pengaruh perubahan suhu terhadap kinerja campuran aspal beton akan dilakukan perendaman pada suhu $60^{\circ} \mathrm{C} ; 70^{\circ} \mathrm{C} ; 80^{\circ} \mathrm{C}$ selama 30 menit dan suhu $60^{\circ} \mathrm{C}$ selama 24 jam sebelum melakukan Marshall Test.

Nilai karakterisik Marshall akan dihitung menggunakan rumus-rumus yang terkait, hasil perhitungan kemudian akan dianalisa dengan menggunakan metode regresi ditampilkan dalam histogram dan berpedoman pada Spesifikasi Umum Divisi VI Revisi 3, Bina Marga (2010), sehingga akan didapatkan kesimpulan dari penelitian ini.

\section{HASIL DAN PEMBAHASAN}

Berdasarkan hasil pengujian sifat fisik aspal dan agregat didapatkan data seperti tertera pada Tabel 1, dapat dilihat bahwa nilai daktilitas, titik lembek, berat jenis aspal, titik nyala dan titik bakar memenuhi persyaratan PEN 60-70.

Tabel 1. Hasil Pengujian Sifat Fisik Aspal

\begin{tabular}{|c|c|c|c|c|c|c|c|}
\hline \multirow[b]{2}{*}{ Pengujian } & \multirow[b]{2}{*}{ Aspal } & \multirow{2}{*}{$\begin{array}{c}\text { Aspal + } \\
\text { HDPE } \\
2 \%\end{array}$} & \multirow{2}{*}{$\begin{array}{c}\text { Aspal + } \\
\text { HDPE } \\
4 \%\end{array}$} & \multirow{2}{*}{$\begin{array}{c}\text { Aspal + } \\
\text { HDPE } \\
6 \%\end{array}$} & \multirow{2}{*}{$\begin{array}{c}\text { Aspal + } \\
\text { HDPE } \\
8 \%\end{array}$} & \multicolumn{2}{|c|}{ Spesifikasi } \\
\hline & & & & & & $\begin{array}{c}\text { Aspal Pen } \\
60-70\end{array}$ & $\begin{array}{c}\text { Aspal } \\
\text { modifikasi }\end{array}$ \\
\hline Berat Jenis & 1,032 & 1,050 & 1,068 & 1,086 & 1,104 & $\geq 1,0$ & $\geq 1,0$ \\
\hline Penetrasi (mm) & 63,83 & 56,33 & 44,67 & 36,17 & 26,33 & $60-70$ & Min.40 \\
\hline Titik Lembek $\left({ }^{\circ} \mathrm{C}\right)$ & 48,5 & 54,5 & 58 & 62,5 & 66,5 & $\geq 48$ & $\geq 54$ \\
\hline Titik nyala/bakar $\left({ }^{\circ} \mathrm{C}\right)$ & 294 & 293,2 & 291,6 & 287,4 & 282,3 & $\geq 232$ & $\geq 232$ \\
\hline Daktilitas (cm) & $\geq 100$ & $\geq 100$ & $\geq 100$ & $\geq 100$ & $\geq 100$ & $\geq 100$ & $\geq 100$ \\
\hline
\end{tabular}

Aspal yang dimodifikasi dengan limbah plastik HDPE mempunyai berat jenis bertambah seiring dengan penambahan plastik HDPE, hal ini dapat menyebabkan semakin mengecilnya rongga dalam campuran aspal modifikasi. Titik lembek juga bertambah seiring dengan penambahan limbah plastik HDPE, hal ini disebabkan aspal mempunyai titik lembek berkisar $48^{\circ} \mathrm{C}$, sedangkan titik leleh plastik HDPE berkisar $134^{\circ} \mathrm{C}$, sehingga aspal menjadi lebih tahan terhadap cuaca. Nilai penetrasi aspal turun seiring dengan penambahan limbah plastik HDPE, sehingga menjadikan aspal agak kaku, namun masih memenuhi syarat daktilitas aspal. Penetrasi aspal pada penambahan limbah plastik HDPE sebesar 6\% tidak memenuhi persyaratan aspal modifikasi.

Pada Tabel 2 dan Tabel 3 terlihat bahwa hasil pengujian sifat fisik agregat halus dan agregat kasar memenuhi Spesifikasi Lapis Perkerasan aspal (Bina Marga revisi 3, 2010). 
Tabel 2. Hasil Pengujian Sifat Fisik Agregat Kasar

\begin{tabular}{|c|c|c|c|}
\hline Pengujian & Standar & $\begin{array}{c}\text { Hasil } \\
\text { Pengujian }\end{array}$ & Spesifikasi \\
\hline $\begin{array}{l}\text { Kekekalan bentuk agregat } \\
\text { terhadap Magnesium Sulfat }\end{array}$ & SNI 3470:2008 & $2 \%$ & Maks. $18 \%$ \\
\hline $\begin{array}{l}\text { Abrasi dengan mesin Los } \\
\text { Angles ( } 500 \text { putaran) }\end{array}$ & SNI 2417:2008 & $12,9 \%$ & Maks. $40 \%$ \\
\hline $\begin{array}{l}\text { Kelekatan Agregat terhadap } \\
\text { aspal }\end{array}$ & SNI 2439:2011 & $90 \%$ & Maks. 95\% \\
\hline $\begin{array}{l}\text { Butiran Pecah Pada agregat } \\
\text { kasar }\end{array}$ & SNI 7619:2012 & $97 / 95$ & $\operatorname{Min} 95 / 90^{*}$ \\
\hline Partikel Pipih dan Lonjong & $\begin{array}{c}\text { ASTM D4791 } \\
\text { Perbandingan 1: } 5\end{array}$ & $0,47 \%$ & Maks. $10 \%$ \\
\hline Material lolos ayakan No. 200 & SNI 03-4142-1996 & $0,25 \%$ & Maks $2 \%$ \\
\hline Pengujian & Standar & $\begin{array}{c}\text { Hasil } \\
\text { Pengujian }\end{array}$ & Spesifikasi \\
\hline Nilai Setara Pasir & SNI 03-4428-1997 & $85 \%$ & Min $60 \%$ \\
\hline $\begin{array}{l}\text { Angularitas dengan uji rongga } \\
\text { udara }\end{array}$ & SNI 03-6877-2002 & 53,95 & Min 45 \\
\hline $\begin{array}{l}\text { Gumpalan Lempung dan } \\
\text { butiran-butiran mudah pecah }\end{array}$ & SNI 03-4141: 1996 & $0,35 \%$ & Maks. $1 \%$ \\
\hline $\begin{array}{l}\text { Material Lolos Ayakan } \\
\text { No. } 200\end{array}$ & $\begin{array}{l}\text { SNI ASTM C117: } \\
2012\end{array}$ & $0,35 \%$ & Maks. $10 \%$ \\
\hline
\end{tabular}

Benda uji Marshall dibuat dengan menggunakan agregat kasar dan agregat halus dengan komposisi $27 \%$ batu pecah $1 / 2,30 \%$ batu pecah $1 / 1,38 \%$ abu batu dan $5 \%$ pasir. Gradasi campuran agregat dapat dilihat pada Gambar 2, di mana memenuhi spesifikasi agregat LASTON AC-BC.

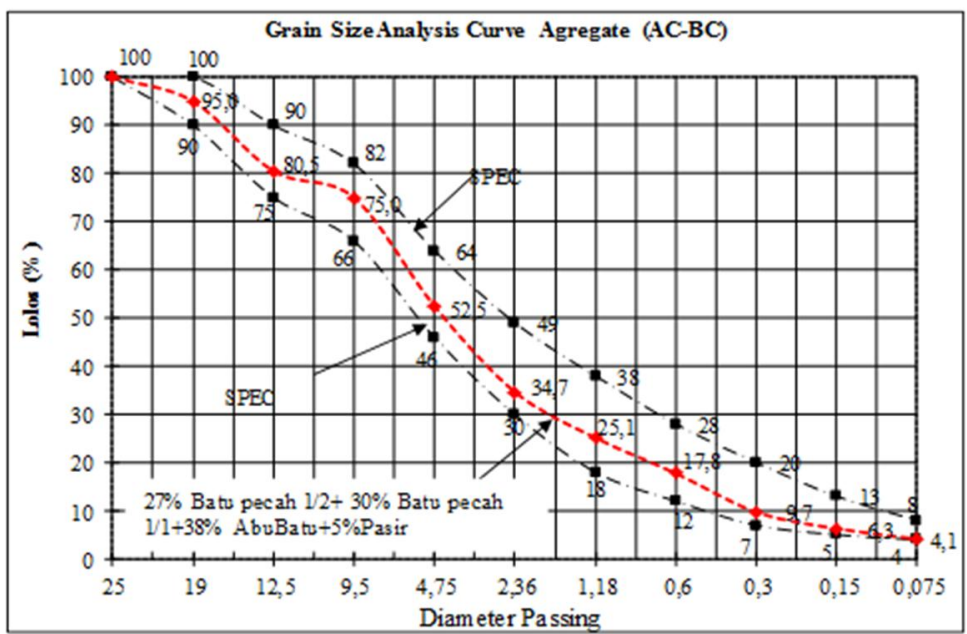

Gambar 2. Grafik Gradasi Agregat Untuk Campuran LASTON (AC-BC) 
Pada Gambar 3, menunjukkan bahwa penambahan plastik mengakibatkan nilai VIM mengalami penurunan dari aspal tanpa plastik berkisar 4,94\% menjadi lebih rendah, kemudian naik seiring dengan bertambahnya kadar plastik dan suhu perendaman. Nilai VIM berdasarkan Spesifikasi Bina Marga yakni antara 3\% - 5\%. Nilai VIM berpengaruh terhadap keawetan lapis perkerasan, semakin tinggi nilai VIM menunjukkan semakin besar rongga dalam campuran. Pada penambahan limbah plastik HDPE $>5,2 \%$, nilai VIM melebihi spesifikasi, hal ini mengakibatkan campuran menjadi kurang rapat, sehingga air dan udara dapat mudah memasuki rongga-rongga dalam campuran yang menyebabkan aspal mudah teroksidasi, dan akan menyebabkan lekatan antar butiran agregat berkurang sehingga berakibat terjadinya pelepasan butiran dan pengelupasan permukaan pada lapisan perkerasan. Nilai VIM yang terlalu rendah akan menyebabkan bleeding karena suhu yang tinggi, viskositas aspal akan menurun sesuai dengan sifat termoplastisnya. Pada saat itu apabila lapis perkerasan menerima beban lalu lintas maka aspal akan terdesak keluar permukaan karena tidak cukupnya rongga bagi aspal untuk melakukan penetrasi dalam lapis perkerasan.

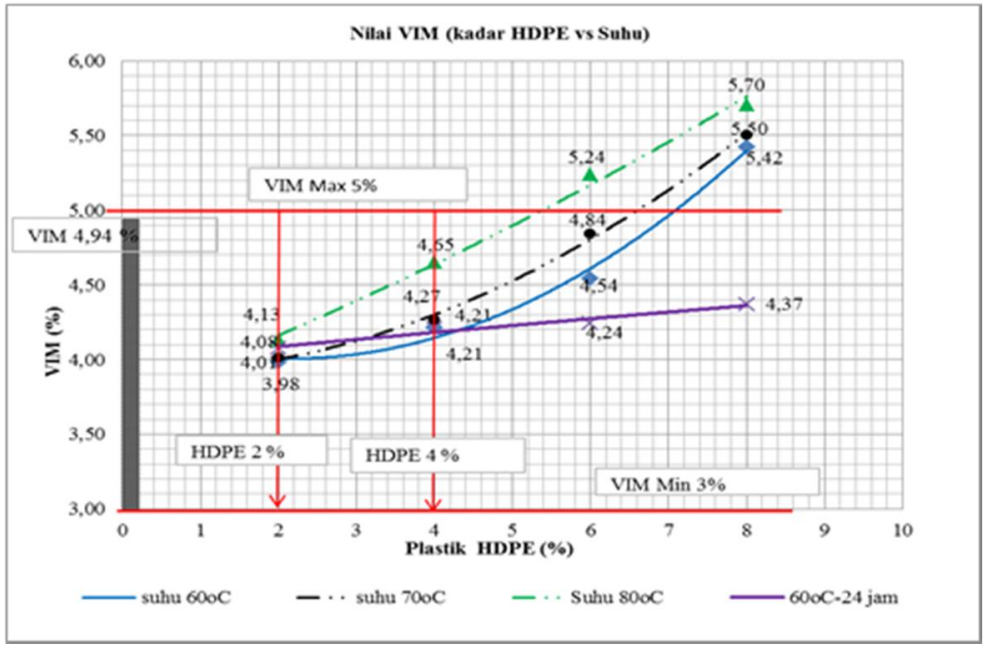

Gambar 3. Nilai Void in The Mix

Stabilitas merupakan kemampuan lapisan untuk menahan deformasi akibat beban lalu lintas yang bekerja diatasnya tanpa mengalami perubahan bentuk, seperti gelombang (wash boarding) dan alur (rutting). Nilai stabilitas dipengaruhi oleh bentuk, kualitas, tekstur permukaan dan gradasi agregat, yaitu gesekan antar butiran agregat (internal friction) dan penguncian antar agregat (interlocking), daya lekat (cohesion) dan kadar aspal dalam campuran. Pada Gambar 4, terlihat bahwa nilai stabilitas mengalami kenaikan seiring dengan penambahan limbah plastik HDPE pada suhu perendaman $60^{\circ} \mathrm{C}$ selama 30 menit. Pada saat perendaman pada suhu $70^{\circ} \mathrm{C}, 80^{\circ} \mathrm{C}$, selama 30 menit dan $60^{\circ} \mathrm{C}$ selama 24 jam mengalami kenaikan dan turun saat penambahan limbah plastik HDPE $>4 \%$, tetapi masih memenuhi nilai stabilitas yang disyaratkan yaitu min $800 \mathrm{~kg}$. Penambahan limbah plastik HDPE sebesar 2-4\% dapat memperbaiki nilai stabilitas Marshall sisa setelah perendaman $60^{\circ} \mathrm{C}$ selama 24 jam yang disyaratkan yaitu sebesar min $90 \%$, sedangkan jika $>4 \%$ justru akan menurunkan kemampuan lapisan untuk menahan deformasi akibat beban lalu lintas. 


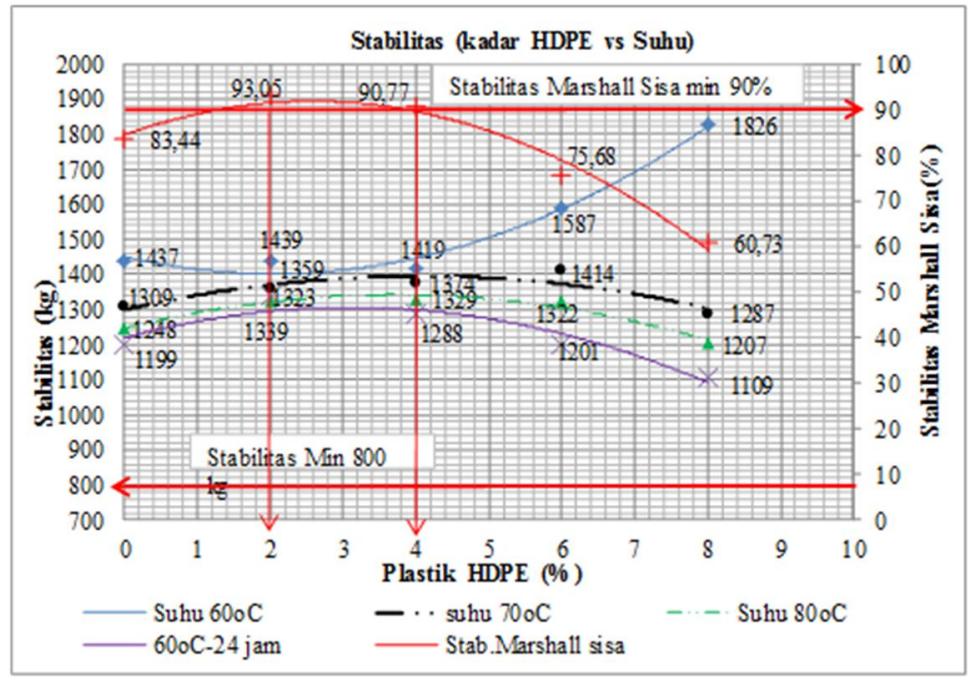

Gambar 4. Stabilitas

Pada Gambar 5, terlihat bahwa nilai flow mengalami penurunan seiring dengan bertambahnya suhu perendaman dan penambahan limbah plastik HDPE . Penambahan limbah plastik HDPE akan memperbaiki kerapatan campuran sehingga nilai flow menjadi lebih rendah. Campuran yang memiliki angka kelelehan rendah dengan stabilitas tinggi cenderung menjadi kaku dan getas. Sedangkan campuran yang memiliki angka kelelehan tinggi dan stabilitas rendah cenderung plastis dan mudah berubah bentuk seperti gelombang (washboarding) dan alur (rutting) apabila mendapat beban lalu lintas oleh sebab itu spesikasi membatasi nilai flow yaitu 2-4 mm. Nilai flow yang rendah akan mengakibatkan campuran menjadi kaku sehingga lapis perkerasan menjadi mudah retak saat dibebani. Jika dilihat dari stabilitas dan nilai flow, penambahan limbah plastik HDPE $>4 \%$ justru akan menjadikan lapisan kaku dan mudah retak.

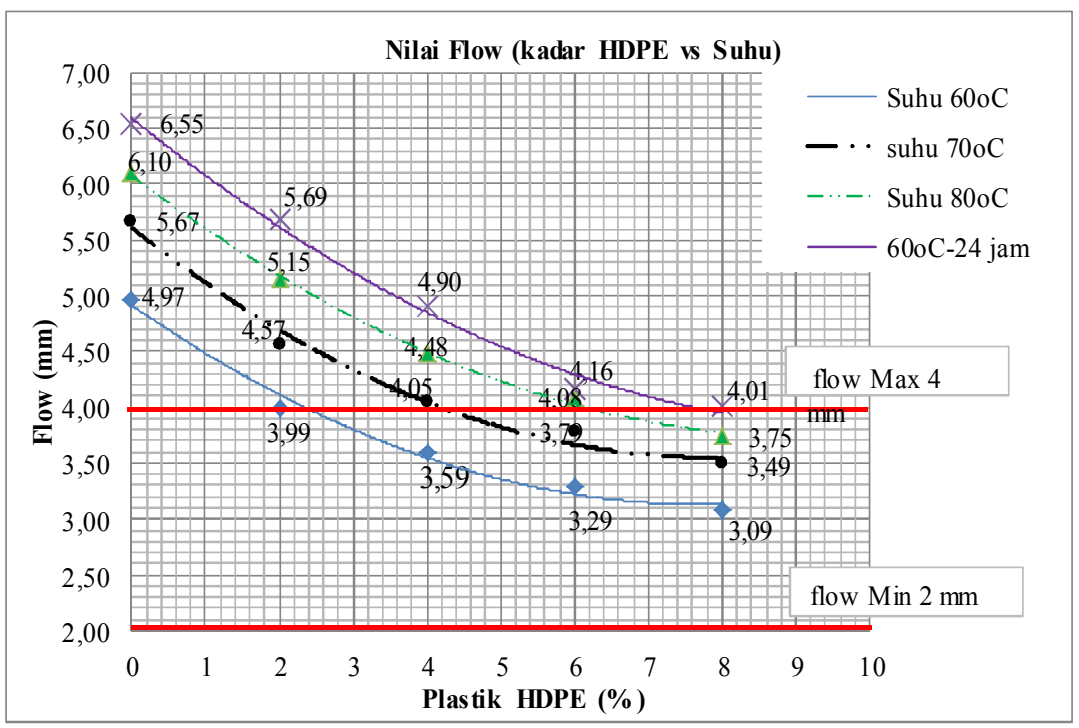

Gambar 5. Nilai Flow 
Hasil penelitian (Gambar 6) menunjukkan bahwa penambahan limbah plastik HDPE meningkatkan nilai VFA, tetapi penambahan limbah plastik HDPE $>2 \%$ mengakibatkan nilai VFA mengalami penurunan, saat penambahan $8 \%$ justru tidak memenuhi nilai spesifikasi yaitu $\min 65 \%$.

Void Filled With Asphalt (VFA) menunjukkan presentase besarnya rongga yang dapat terisi oleh aspal. Nilai VFA yang semakin tinggi berarti semakin banyak rongga dalam campuran yang terisi aspal sehingga kekedapan campuran terhadap air dan udara juga semakin tinggi, tetapi nilai VFA yang terlalu tinggi akan menyebabkan bleeding. Nilai $V F A$ yang terlalu kecil akan menyebabkan campuran kurang kedap terhadap air dan udara karena lapisan film aspal akan menjadi tipis dan akan mudah retak bila menerima penambahan beban sehingga campuran aspal mudah teroksidasi yang akhirnya menyebabkan lapis perkerasan tidak tahan lama.

Hasil penelitian pada Gambar 6 terlihat bahwa nilai VFA bertambah seiring dengan bertambahnya suhu perendaman. Namun sebaliknya saat ditambahkan limbah plastik HDPE nilai VFA akan turun seiring dengan bertambahnya suhu perendaman. Jadi dapat disimpulkan bahwa: semakin banyak limbah plastik HDPE yang ditambahkan tidak memberikan nilai tambah pada campuran, sebaiknya dibatasi $2-4 \%$ agar didapatkan campuran yang kedap air dan tahan lama serta tidak mudah retak.

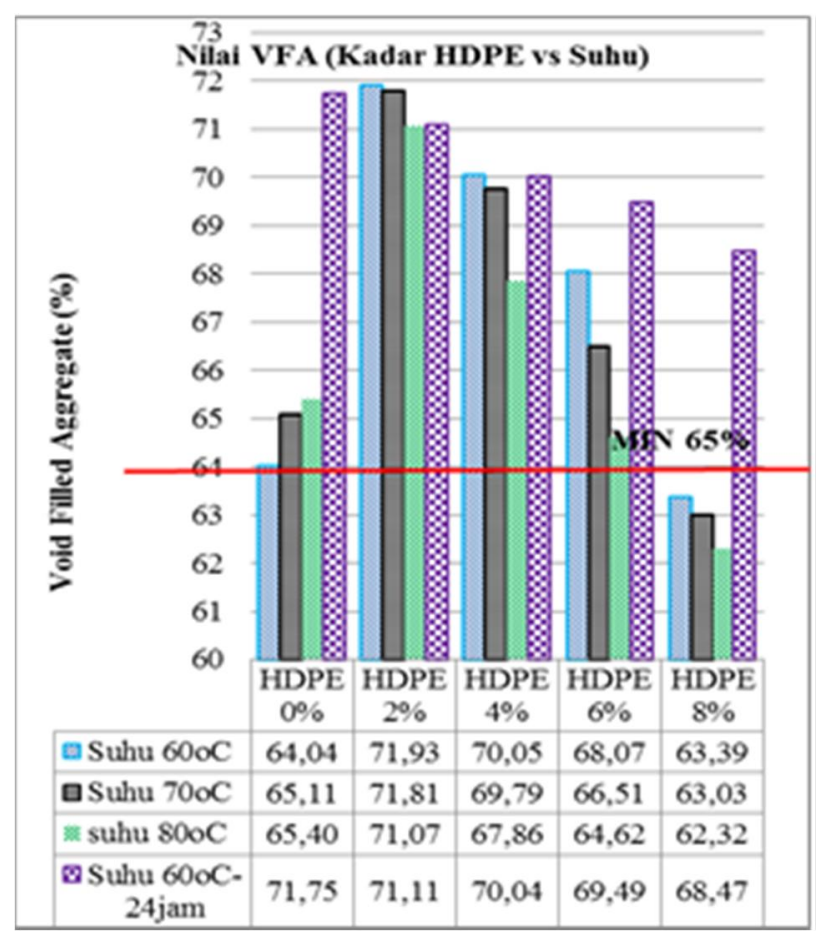

Gambar 6. Void Filled with Asphalt

Void in Mineral Agregat (VMA) yaitu rongga udara yang ada diantara partikel campuran agregat aspal yang sudah dipadatkan termasuk ruang yang terisi aspal yang dinyatakan dalam persen terhadap total volume campuran agregat aspal. Nilai VMA yang diharapkan dalam campuran beraspal yaitu seminimum mungkin, dengan tujuan untuk memberikan ruang yang cukup pada aspal agar dapat melekat pada agregat. 
Faktor-faktor yang mempengaruhi nilai VMA antara lain gradasi agregat, kadar aspal, dan metode pemadatan. Pada Gambar 7, terlihat bahwa nilai VMA bertambah seiring dengan bertambahnya limbah plastik HDPE dan suhu perendaman. Pada perendaman selama 24 jam nilai VMA tanpa limbah plastik HDPE lebih rendah dari spesifikasi, sedangkan saat ditambahkan limbah plastik HDPE naik sampai batas penambahan 4\% terjadi penurunan. Jadi semakin banyak HDPE yang ditambahkan ke dalam aspal tidak memberikan manfaat yang lebih baik terhadap cuaca/suhu dan campuran, malah akan mengurangi daya lekat aspal terhadap agregat.

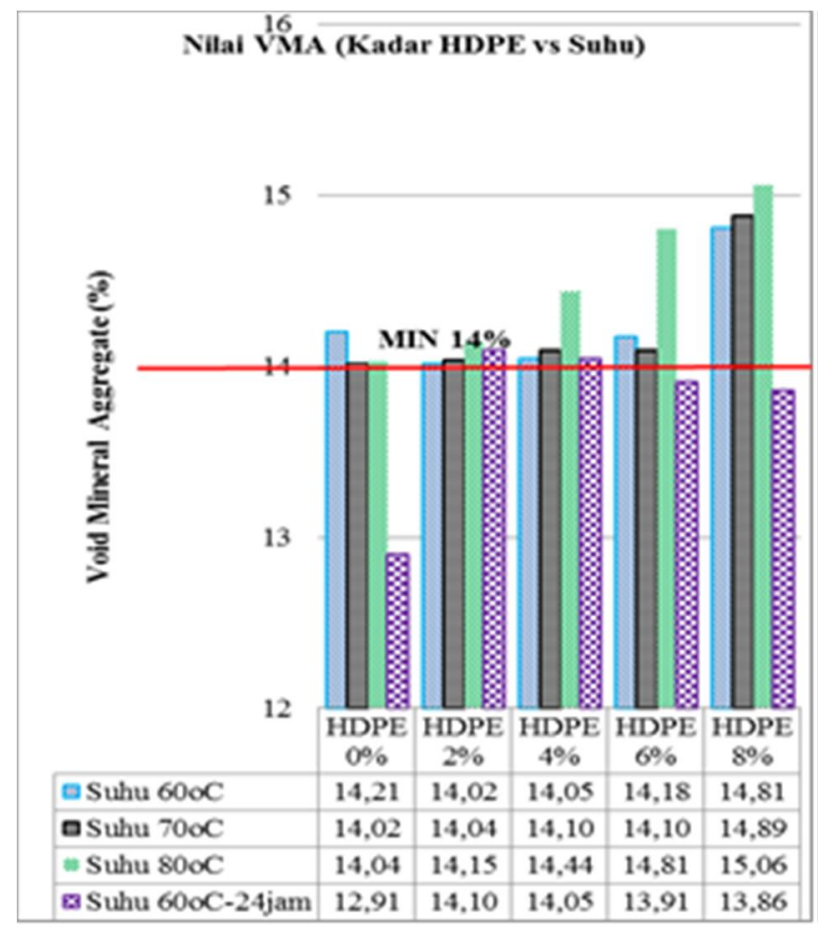

Gambar 7. Void in Mineral Aggregate

\section{KESIMPULAN}

Dari hasil penelitian yang dilakukan terhadap campuran aspal beton lapis AC-BC menggunakan limbah plastik HDPE sebagai bahan tambah didapat simpulan bahwa:

a. Aspal yang dimodifikasi dengan limbah plastik HDPE yang memenuhi Spesifikasi Umum Divisi VI Revisi 3, Bina Marga, 2010 yaitu sebesar $<4 \%$.

b. Limbah plastik HDPE yang dapat ditambahkan pada campuran aspal beton (ACBC) berkisar 2-4 \% terhadap berat aspal, yang memenuhi nilai karakteristik Marshall dan tahan terhadap cuaca ekstrem.

\section{DAFTAR PUSTAKA}

[1] Anita Rahmawati. 2017. Perbandingan Penggunaan Polypropilene (PP) dan High Density Polyethylene (HDPE) pada Campuran LASTON (AC-WC). Media Teknik Sipil, Volume 15, Nomor 1, Februari, hal 11-19.

[2] Anurag V. Tiwari and Y R M Rao. 2017. Study of Plastic Waste Mixed Bituminous Concrete Using Dry Process for Road Construction[Electronic version]. The Asian Review of Civil Engineering. Vol.. 6 No.2, 2017, pp.1-6. 
[3] Bina Marga. 2010. Perkerasan Aspal, Spesifikasi Umum Divisi VI Revisi 3, Jakarta

[4] Madhava Reddy, N dan Venkatasubbaiah, M.C. 2017. Effects of high density polyethylene and crumb rubber powder on properties of asphalt mix [Electronic version]. International Research Journal of Engineering and Technology, Volume: 04 Issue: 06, June, 2572-2578.

[5] Ronna Nirmala. 2017. Aspal campur limbah plastik: efisien dan tahan banting, Beritagar.id. Selasa, 01 Agustus.

[6] Sevil Kofteci. 2016. Effect of HPDE Based Wastes on the Performance of Modified Asphalt Mixtures [Electronic version]. Procedia Engineering 161, pp. $1268-1274$.

[7] Savita Devi, Rupesh kumar, Shad Ahmad, Jitendra Kumar Dhawan dan Premchand Yadav. 2016. Partial Replacement of Bitumen by using Plastic Waste in Bitumen Concrete [Electronic version]. SSRG International Journal of Civil Engineering, volume 3, Issue 7, July, pp. 79-81.

[8] Vijay Rohilla, Paramjeet Malik. 2016. Use of Waste High Density Polyethylene as Bitumen Modifier in Asphalt Concrete Mix[Electronic version]. International Journal of All Research Education and Scientific Methods (IJARESM). Volume 4, Issue 7, July, pp 237-242. 